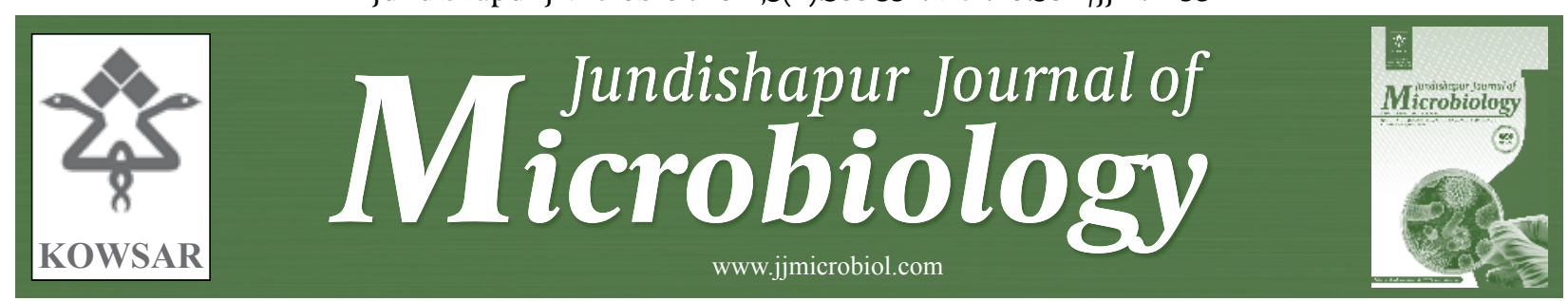

\title{
Vinegar as a Removing Agent of Candida albicans From Acrylic Resin Plates
}

\author{
Abbas Ali Jafari ${ }^{1}$, Abbas Falah-Tafti ${ }^{2}$, Mohammad Hossein Lotfi-Kamran ${ }^{2}$, Arezzo Zahraeii ${ }^{3}$, \\ Abdolhassan Kazemi ${ }^{4}$ \\ ${ }^{1}$ Department of Medical Parasitology \& Mycology, School of Medicine, Shahid Sadoughi University of Medical Sciences, Yazd, IR Iran \\ ${ }^{2}$ Department of Prostodontics, School of Dentistry, Shahid Sadoughi University of Medical Sciences, Yazd, IR Iran \\ ${ }^{3}$ Shahid Sadoughi University of Medical Sciences, Yazd, IR Iran \\ ${ }^{4}$ Infections and Tropical Disease Research Center of Immunology, Tabriz University of Medical Sciences, Tabriz, IR Iran
}

\begin{tabular}{l} 
A R T I C L E I N F O \\
\hline Article type: \\
Original Article \\
\hline Article history: \\
Received: 03 Oct 2011 \\
Revised: 04 Nov 2011 \\
Accepted: 20 Nov 2011 \\
\hline
\end{tabular}

\begin{abstract}
A B S T R A C T
Background: Adherence of Candida species, mainly C. albicans to denture surfaces, forms a biofilm which causes denture stomatitis in denture users. Removal of Candida plaque on dentures is essential to control the colonization of this yeast and to prevent infections related to C. albicans.

objectives: The aim of this study was to compare the effectiveness of sodium hypochlorite with white vinegar for the disinfection of C. albicans from acrylic resin.

Materials and Methods: $82,10 \times 10 \times 1 \mathrm{~mm}$ acrylic resin plates were inoculated with $1 \times 10^{3} \mathrm{C}$. albicans suspension for 24 hours to prepare experimental Candida biofilm. The total number of Candida cells which adhered to 10 acryl resin plates was determined and the remaining 72 plates were randomly divided into four groups. The test plates were immersed in a solution of $1 \%$ sodium hypochlorite, $5 \%$ or $10 \%$ white vinegar for a period of 8 hours and distilled water was used as the negative control group. The Candida removing ability of the 3 disinfectants and the negative control group was assessed by comparing the number of colony forming units per $1 \mathrm{~mL}$ of the plates washing solution before and after the removing protocol. Data was analyzed using Kruskal-Wallis and Mann-Whitney tests.

Results: Sodium hypochlorite (1\%) and white vinegar (10\%) removed $100 \%$ of the C. albicans cells, followed by white vinegar (5\%), which removed $99 \%$ of the adhered C. albicans from the acrylic resin plates. There wasn't any significant statistical difference found between the $5 \%$ and $10 \%$ white vinegar in removing Candida from the acryl resin plates $(P=0.161)$.

Conclusions: Overnight immersion of complete removable dentures in $10 \%$ or even a $5 \%$ white vinegar solution effectively removed C. albicans cells that had adhered to the denture surface and their removal properties the same as $1 \%$ sodium hypochlorite.
\end{abstract}

Copyright $\odot 2012$ Kowsar Corp. All rights reserved.

Implication for health policy/practice/research/medical education:

The results of this study indicate that vinegar is useful for removing of Candida biofilm from complete removable denture.

Please cite this paper as:

Jafari AA, Falah-Tafti A,Lotfi-Kamran MH, Zahraeii A, Kazemi A. Vinegar as a Removing Agent of Candida albicans From Acrylic Resin Plates. Jundishapur J Microbiol. 2012; 5(2):388-92. DOI: 10.5812/jjm.2499

* Corresponding author: Abbas Fallah-Tafti, Department of Prostodontics, School of Dentistry, DahaFajr Boulvard, Yazd, IR Iran. Tel: +98-3518228717, Fax:+98-3518367636, E-mail:Jaabno@gmail.com

DOI: $10.5812 / j$ jim.2499

Copyright @2012 Kowsar Corp. All rights reserved.

\section{Background}

Denture stomatitis, formerly known as denture sore mouth, relates to an inflammatory lesion of the mucosa followinthe use of complete or partial removable dental prostheses in about $60 \%$ of denture wearers (1). Candida species, which are a part of the human oral microbial flora in particular C. albicans, are the main etiologic agents responsible for the development of this opportunistic infec- 
tion (2). Poor oral hygiene, badly fitting dentures and using denture liners are the most common causes of denture stomatitis (3). The ability of C. albicans to adhere to host mucosal tissues (4) as well as acrylic denture surfaces (5), the production of proteolytic enzymes that prepare penetration into tissues, phenotype switching of yeast to the hyphal form (6) and several immunomodulatory activities are known to be virulent factors for this fungus (7). Salivary flow is also reduced in patients with dentures, which decreases the physiological cleaning properties of the tongue and prepares a suitable environment for microbial survival and colonization in the oral cavity of denture users (8). Attachment and colonization of Candida on the surface of the denture, produces biofilm that is implicated as a possible source for oral and disseminated candidiasis in immunocompromisedpatients and denture wearers with poor oral hygiene $(9,10)$, cleaning and removal of this biofilm is necessary for the control of denture stomatitis in edentulous patients $(11,12)$. There are many studies in the literature suggesting the use of mechanical, chemical and even a combination of both methods for denture hygiene (13-16). Immersion of dentures in a commercial or a household solution is a commonly used chemical for the disinfection of denture biofilm. Several cleaning agents that are relatively expensive and to damage the acrylic resin and metal alloys of the dentures were also reported $(17,18)$.

Vinegar is a sour liquid comprised mainly of acetic acid, which is prepared in households by the fermentation of fruit such as grapes and apples in Iran. This solution is also commercially available, it is cheap and easily found in Iranian markets. There are many studies which support the antimicrobial effects of vinegar (19-22). Vinegar has also been shown to be effective in the prevention and control of microbial contamination in intra-canal treatment of apical periodontitis in dog teeth (23).

\section{Objectives}

The general purpose of the present study was to evaluate the effectiveness of household and commercial vinegar for disinfecting C. albicans from acrylic resin.

\section{Materials and Methods}

\subsection{Preparation of Acrylic Resin Plates}

82 square shaped, $10 \times 10 \times 1 \mathrm{~mm}$, acrylic resin plates (Acropars, Iran) were prepared using thermally activated acrylic resin according to the manufacturer's instructions (Figure 1). The specimens were kept in a flask containing physiological serum $(\mathrm{NaCl} 0.85 \%)$, sterilized in an autoclave (Labtron, Iran) at $121^{\circ} \mathrm{C} / 15 \mathrm{~min}$ and incubated at $4^{\circ} \mathrm{C}$ for adherence testing.

\subsection{Preparation of Fungal Suspension and Experimen- tal Biofilm}

A standard strain of C. albicans (ATCC 10231) was cultured on Sabouraud dextrose agar plates (Merck, Germany) and incubated at $37^{\circ} \mathrm{C}$ for 24 hours. A suspension containing

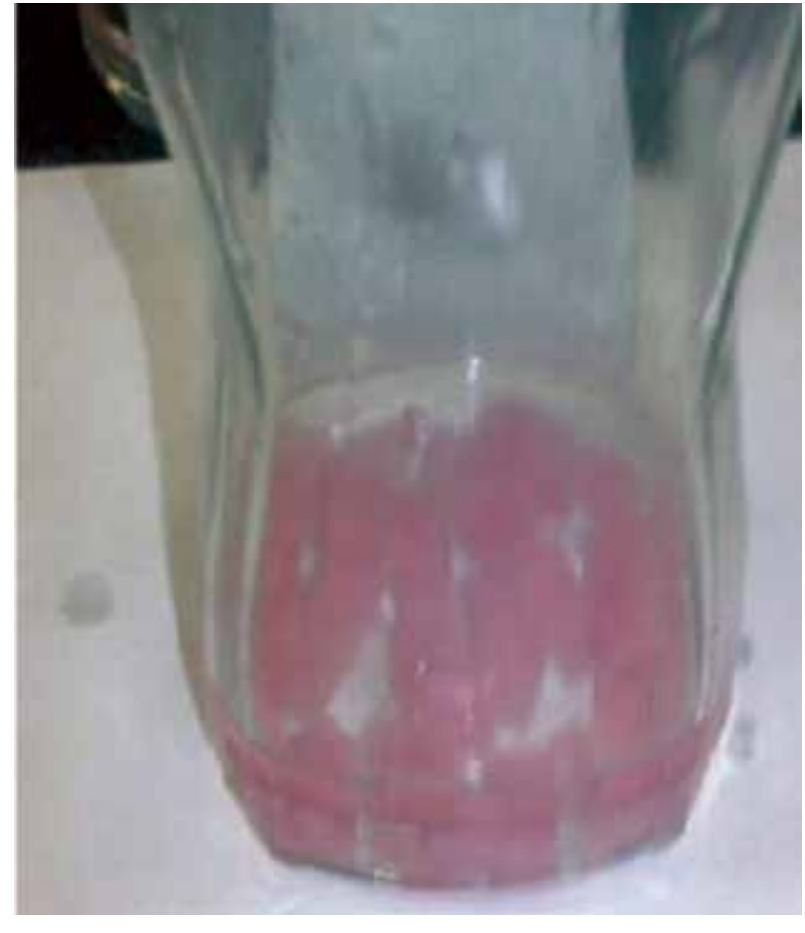

Figure 1. Standard Acrylic Resin Plates $(10 \times 10 \times 1 \mathrm{~mm})$

$1 \times 10^{3}$ viable cells per milliliter was prepared in a sterile saline solution ( $\mathrm{NaCl} 0.85 \%$ ) using a haemocytometer slide. Experimental biofilm was created using 24 well cell culture plates by adding $1.5 \mathrm{~mL}$ sterile Sabouraud Broth, one acrylic resin plate and $100 \mu \mathrm{L}$ of $C$. albicans suspension were added to each well. The plates were sealed and incubated at $37^{\circ} \mathrm{C}$ in a shaker (100 rpm) for 24 hours to prepare the experimental C. albicans plaque. The acrylic resin plates were then washed 3 times with $1 \mathrm{~mL}$ of sterile distilled water and used for the removing test. Ten plates were transferred to 10 falcon tubes containing $1 \mathrm{ml}$ of sterile physiological solution $(\mathrm{NaCl} 0.85 \%)$ and glass pearls, then agitated in a Sonicator (Elma, Germany) for 5 minutes ( $45 \mathrm{KH} / 5 \mathrm{~min}$ ) to remove the adhered cells. $10 \mu \mathrm{L}$ of each suspension was added to $90 \mu \mathrm{L}$ of sterile physiological solution and plated in duplicate on Sabouraud dextrose agar plates. All plates were incubated

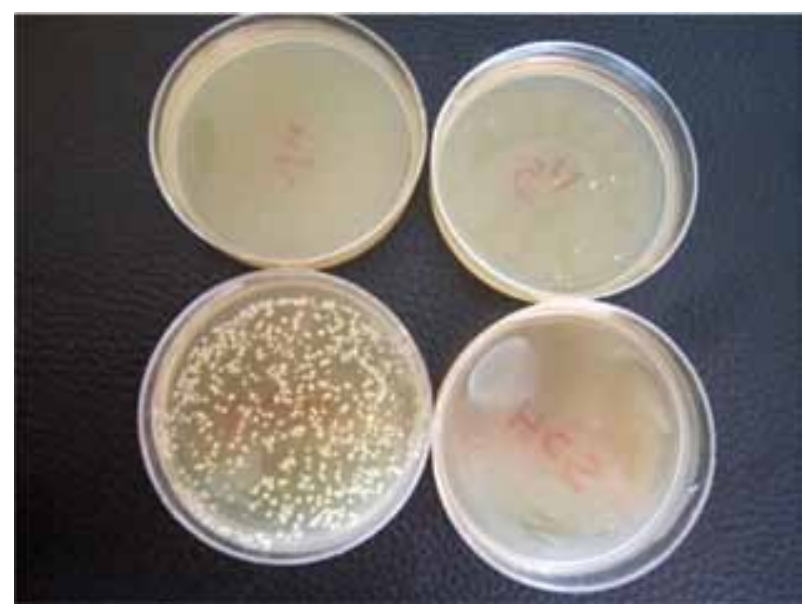

$\overline{\text { Figure 2. Isolated C. albicans Colonies From Culture of } 10 \mu \mathrm{L} \text { of Washing }}$ Solution 
for 48 hours at $37^{\circ} \mathrm{C}$ and the number of colony-forming units per $1 \mathrm{~mL}$ of the plates' washing solution (cfu/mL) was determined by the number of attached Candida cells before entering the removing protocol (Figure 2).

\subsection{Removal of Candida}

Acrylic resin plates covered in plaque were then randomly divided into 4 groups of 18 . Group 1 plates were immersed in $50 \mathrm{~mL}$ 10\% white vinegar (Yek \& Yek, Iran), group 2 in $5 \%$ white vinegar (grape), group 3 in $1 \%$ sodium hypochlorite, and group 4 in distilled water as a negative control, then incubated at $37^{\circ} \mathrm{C}$ for 8 hours in a shaker (100 rpm). After incubation, the plates were washed 5 times with $1 \mathrm{~mL}$ of sterile distilled water and transferred to sterile falcon tubes for examination of the number of viable Candida cells that had adhered to the plates as described previously. The Candida removing ability of the three disinfectants and the negative control group were assessed by comparing the number of colonyforming units per $1 \mathrm{~mL}$ of plate washing solution before and after the removing procedure.

\subsection{Statistical Tests}

A Kruskal-Wallis test was used to compare the average viable number of Candida cells in the four groups. A Mann-Whitney test was also used to compare the results in the $5 \%$ and $10 \%$ vinegar groups. Differences in the Candida removing ability of the tested chemicals were considered significant if $P<0.05$. All statistical calculations were performed using SPSS15 software.

\section{Results}

The mean value of viable $C$. albicans cells which adhered to the acrylic resin plates before and after disinfection, as well as the percentage that were removed are illustrated in Table 1. Candida growth was not present in the culture of group 1 and group 3 plates, meanwhile the mean value of $\mathrm{CFU} / \mathrm{mL} \pm \mathrm{SD}$ is shown in Table 1 . The $10 \%$ vinegar and $1 \%$ sodium hypochlorite groups showed the highest rate of C. albicans removal from the acrylic resins (100\%) followed by $5 \%$ vinegar (99\%) when compared to the number of viable Candida cells before the removing procedure in the control group. There was no statistically significant difference between the vinegar at 5\% and 10\% $(P=0.161)$ or sodium hypochlorite in removing Candida from the resin plates. In fact all three disinfectants presented statistically significant differences when compared with the before and after removing protocol $(P<0.01)$.

\section{Discussion}

Denture stomatitis is a prevalent disorder in patients using dentures caused mainly by the adherence and colonization of $C$. albicans on the surface of the denture. This results in direct cytotoxicity and produces an inflammatory effect on the mucosal epithelium that covers the denture bearing tissues $(8,24)$. There are several previous studies which have shown that disinfection of complete dentures with sodium hypochlorite is an effective treatment $(25,26)$, however there is controversy over the effectiveness of white vinegar in the prevention and treatment of denture stomatitis and its ability to completely remove $C$. albicans adhered to the surface of the acrylic resin $(27,28)$.

In the present study, disinfecting C. albicans from the surface of acrylic resin plates using $1 \%$ sodium hypochlorite, $5 \%$ and $10 \%$ white vinegar solutions were compared for their removing abilities. There are several methods which have been used for evaluating the plaque removing efficacy of denture disinfectants. Experimental in vitro formation of Candida biofilm on the surface of acrylic resin plates and quantitative assessment of the remaining viable Candida adheredto the plates is more accurate than other methods such as weight (29) and staining methods (30) suggested by some investigators. White vinegar is a readily available, inexpensive household solution usually found in Iranian homes, which was used in the current study for the removal of C. albicans biofilm on acryl resins. $10 \%$ white vinegar and $1 \%$ sodium hypochlorite solutions were shown to be equally effective as both removed $100 \%$ of the $C$. albicans yeast adhered to the resin plates. The $5 \%$ white vinegar solution also showed effective removing properties eliminating $99 \%$ of the attached $C$. albicans cells from the surface of the resin plates $(P=0.161)$.

These results were comparable with a study by Basson et al. who also reported the effectiveness of undiluted vinegar for killing adherent microorganisms when used as a disinfection agent for denture cleansing (27), conversely Pinto et al. in a recent study reported that 10\% vinegar wasn't able to eliminate $C$. albicans counts on the dentures and saliva of denture users (28). However the removing property of $10 \%$ vinegar was a little higher than $5 \%$ white vinegar for eradicating Candida from acryl plates in the current study, but this wasn't statistically significant $(P=0.161)$, representing the same level of effectiveness. In vitro experimental studies have already shown that low doses of vinegar can induce apoptosis

\begin{tabular}{lllll}
\hline \multicolumn{2}{l}{ Table 1: Disinfectant Effectiveness in Removing C. albicans From Acryl Resins } & & \\
\hline Disinfectants & Initial Culture, Mean \pm SD & C. albicans After the Protocol, Mean \pm SD & Removing Ability, \% & $P$ value \\
\hline $10 \%$ vinegar & $1.32 \times 10^{3} \pm 1.1 \times 10^{2}$ & - & $100 \%$ & 0.0001 \\
$5 \%$ vinegar & $1.32 \times 10^{3} \pm 1.1 \times 10^{2}$ & $1.3 \pm 2.7$ & $99 \%$ & 0.001 \\
$1 \%$ sodium hypochlorite & $1.32 \times 10^{3} \pm 1.1 \times 10^{2}$ & - & $100 \%$ & 0.0001 \\
D.W. (negative control) & $1.32 \times 10^{3} \pm 1.1 \times 10^{2}$ & $1.25 \times 10^{3} \pm 1.06 \times 10^{2}$ & $5.3 \%$ & 0.18 \\
\hline
\end{tabular}


and programmed cell death of C. albicans (31). The acetic acid present in vinegar is also used to control other pathogenic fungi such as dermatophytes, the agent of tineapedis (32). Komayama et al. (33) in their study reported that $50 \%$ vinegar was not effective for disinfecting C. albicans on toothbrushes; however it was useful for several bacteria such as Streptococcus mutans, Streptococcus pyogenes and Staphylococcus aureus (33).

Immersion of acryl plates in $1 \%$ sodium hypochloritewas also effective for removing Candida from acryl resin plates, removing $100 \%$ of the attached Candida in the present study. The presence of undissociatedhypochlorous acid (HCOl), the concentration of which is dependent on $\mathrm{pH}$, oxidizes the sulfhydryl groups (-SH) of amino acids and proteins to produce disulphide forms $(\mathrm{S}-\mathrm{S})(34,35)$. There are many studies which have proven the effectiveness of $1 \%$ sodium hypochlorite in removing Candida species from the surface of dentures as shown in this current study. However it produces an unpleasant smell and taste, which must be properly washed to remove the product when used for disinfecting dentures. Continuoususe of sodium hypochlorite can also produce stains on the surface of the dentures and damage them $(14,16)$, which did not occur with the use of $10 \%$ vinegar (28).

Soaking dentures overnight in $10 \%$ or even $5 \%$ vinegar solution effectively removed C. albicans cells adhered to the denture surface. The removing effect of both $5 \%$ and $10 \%$ vinegar solutions is comparable with $1 \%$ sodium hypochlorite.

\section{Acknowledgments}

This work has been supported by Deputy of research from Shahid Sadoughi University of Medical Sciences (Thesis number 1428). The authors would like to thank Farzaneh Mirzaei for her kind help in the laboratory works.

\section{Financial Disclosure}

None Declared.

\section{Funding/Support}

None Declared.

\section{References}

1. Geerts GA, Stuhlinger ME, Basson NJ. Effect of an antifungal denture liner on the saliva yeast count in patients with denture stomatitis: a pilot study. J Oral Rehabil. 2008;35 (9):664-9.

2. Daniluk T, Tokajuk G, Stokowska W, Fiedoruk K, Sciepuk M, Zaremba ML, et al. Occurrence rate of oral Candida albicans in denture wearer patients. Adv Med Sci. 2006;51 (Suppl 1):77-80.

3. Webb BC, Thomas CJ, Willcox MD, Harty DW, Knox KW. Candidaassociated denture stomatitis. Aetiology and management: a review. Part 2. Oral diseases caused by Candida species. Aust Dent J.1998;43 (3):160-6.

4. Hazen KC, Brawner DL, Riesselman MH, Jutila MA, Cutler JE. Differential adherence of hydrophobic and hydrophilic Candida albicans yeast cells to mouse tissues. Infect Immun. 1991;59
(3):907-12.

5. Radford DR, Challacombe SJ, Walter JD. Denture plaque and adherence of Candida albicans to denture-base materials in vivo and in vitro. Crit Rev Oral Biol Med.1999;10 (1):99-116.

6. Odds F. Candida and candidosis: a review and bibliography. Candida and candidosis: a review and bibliography 2nd edition. 1988.

7. Schaller M, Mailhammer R, Grassl G, Sander CA, Hube B, Korting HC. Infection of human oral epithelia with Candida species induces cytokine expression correlated to the degree of virulence. J Invest Dermatol. 2002;118 (4):652-7.

8. Budtz-Jorgensen E. Clinical aspects of Candida infection in denture wearers. J Am Dent Assoc. 1978;96 (3):474-9.

9. Martin BJ, Corlew MM, Wood H, Olson D, Golopol LA, Wingo M, et al. The association of swallowing dysfunction and aspiration pneumonia. Dysphagia. 1994;9 (1):1-6.

10. Nikawa H, Hamada T, Yamashiro $\mathrm{H}$, Kumagai $\mathrm{H}$. A review of in vitro and in vivo methods to evaluate the efficacy of denture cleansers. Int J Prosthodont. 1999;12 (2):153-9.

11. Budtz-Jorgensen E, Mojon P, Rentsch A, Deslauriers N. Effects of an oral health program on the occurrence of oral candidosis in a long-term care facility. Community Dent Oral Epidemiol. 2000;28 (2):141-9.

12. Kulak-Ozkan Y, Kazazoglu E, Arikan A. Oral hygiene habits, denture cleanliness, presence of yeasts and stomatitis in elderly people. J Oral Rehabil. 2002;29 (3):300-4.

13. Consani RL, Azevedo DD, Mesquita MF, Mendes WB, Saquy PC. Effect of repeated disinfections by microwave energy on the physical and mechanical properties of denture base acrylic resins. Braz Dent J. 2009;20 (2):132-7.

14. Cunegatti Zottis A, Caldas Cosme D, Brasiliense Elsemann R, Mitsuo Silva Oshima H, Arai Shinkai RS. Changes in hardness and surface topography of tissue conditioners submitted to chemical disinfection. Minerva Stomatol. 2008;57 (11-12):577-85.

15. Paranhos Hde F, Davi LR, Peracini A, Soares RB, Lovato $\mathrm{CH}$, Souza RF. Comparison of physical and mechanical properties of microwave-polymerized acrylic resin after disinfection in sodium hypochlorite solutions. Braz Dent J. 2009;20 (4):331-5.

16. Pinto Lde R, Acosta EJ, Tavora FF, da Silva PM, Porto VC. Effect of repeated cycles of chemical disinfection on the roughness and hardness of hard reline acrylic resins. Gerodontology. 2010;27 (2):147-53.

17. Arita M, Nagayoshi M, Fukuizumi T, Okinaga T, Masumi S, Morikawa M, et al. Microbicidal efficacy of ozonated water against Candida albicans adhering to acrylic denture plates. Oral Microbiol Immunol. 2005;20 (4):206-10.

18. Jagger DC, Harrison A. Denture cleansing--the best approach. $\mathrm{Br}$ Dent J.1995;178 (11):413-7.

19. Nascimento MS, Silva N, Catanozi MP, Silva KC. Effects of different disinfection treatments on the natural microbiota of lettuce. J Food Prot. 2003;66 (9):1697-700.

20. Vijayakumar C, Wolf-Hall C. Minimum bacteriostatic and bactericidal concentrations of household sanitizers for Escherichia coli strains in tryptic soy broth. Food Microbiol. 2002;19 (4):383-8.

21. Vijayakumar C, Wolf-Hall CE. Evaluation of household sanitizers for reducing levels of Escherichia coli on iceberg lettuce. J Food Prot. 2002;65 (10):1646-50.

22. Wu FM, Doyle MP, Beuchat LR, Wells JG, Mintz ED, Swaminathan B. Fate of Shigella sonnei on parsley and methods of disinfection.J Food Prot. 2000;63 (5):568-72.

23. Estrela C, Holland R, Bernabe PF, de Souza V, Estrela CR. Antimicrobial potential of medicaments used in healing process in dogs' teeth with apical periodontitis. Braz Dent J. 2004;15 (3):181-5.

24. Sherman RG, Prusinski L, Ravenel MC, Joralmon RA. Oral candidosis. Quintessence Int. 2002;33 (7):521-32.

25. Falah-Tafti A, jafari AA, Lotfi-Kamran MH. Comparison of the Effectiveness of Sodium Hypochlorite and Dentamize Tablet for Denture Disinfection. World J Med Sci. 2008;3 (1):10-4.

26. Pavarina AC, Pizzolitto AC, Machado AL, Vergani CE, Giampaolo ET. An infection control protocol: effectiveness of immersion solutions to reduce the microbial growth on dental prostheses. J Oral Rehabil. 2003;30 (5):532-6.

27. Basson NJ, Quick AN, Thomas CJ. Household products as sa- 
nitising agents in denture cleansing. J Dent Assoc S Afr. 1992;47 (10):437-9.

28. Pinto TM, Neves AC, Leao MV, Jorge AO. Vinegar as an antimicrobial agent for control of Candida spp. in complete denture wearers. J Appl Oral Sci. 2008;16 (6):385-90.

29. SharP EW, Verran J. Denture cleansers and in vitro plaque.J Prosthet Dent. 1985;53 (4):584-5.

30. Canay S, Erguven S, Yulug N. The function of enzymes in removing Candida accumulated on denture plaque. J Islamic Acad Sci. 1991;4 (1):87-9.

31. Phillips AJ, Crowe JD, Ramsdale M. Ras pathway signaling accelerates programmed cell death in the pathogenic fungus Candida albicans. Proc Natl Acad Sci U S A. 2006;103 (3):726-31.
32. Gemeinhardt H. [Disinfection of shoes for the killing of tinea pedis fungi using peracetic acid]. Dtsch Gesundheitsw. 1972;27 (13):614-5.

33. Komiyama EY, Back-Brito GN, Balducci I, Koga-Ito CY. Evaluation of alternative methods for the disinfection of toothbrushes. Braz Oral Res. 2010;24 (1):28-33.

34. Arnhold J, Hammerschmidt S, Arnold K. Role of functional groups of human plasma and luminol in scavenging of $\mathrm{NaOCl}$ and neutrophil-derived hypochlorous acid. Biochim Biophys Acta.1991;1097(2):145-51.

35. Webb BC, Willcox MD, Thomas CJ, Harty DW, Knox KW. The effect of sodium hypochlorite on potential pathogenic traits of Candida albicans and other Candida species. Oral Microbiol Immunol. 1995;10 (6):334-41. 